\title{
Prediksi Erosi di Wilayah Jawa Timur
}

\author{
Rhoshandhayani Koesiyanto Taslim¹, Marga Mandala1 ${ }^{1}$ dan Indarto Indarto*1
}

1Program Studi Magister Pengelolaan Sumberdaya Air Pertanian Pascasarjana Universitas Jember; email: indarto.ftp@unej.ac.id

\begin{abstract}
ABSTRAK
Erosi adalah peristiwa pengikisan tanah yang terjadi secara alamiah. Seiring bertambahnya jumlah penduduk di wilayah Jawa Timur, maka aktivitas konversi fitur peruntukan lahan alami (hutan, perkebunan, pedesaan) menjadi pusat aktivitas manusia (hunian, perkotaan) akan memicu peningkatan erosi. Penilaian potensi erosi secara cepat untuk wilayah yang luas diperlukan dalam rangka perencanaan konservasi lahan. Penelitian ini bertujuan untuk menghitung tingkat erosi di Jawa Timur dengan menggunakan metode USLE (Universal Soil Loss Equation) dan GIS. Faktor erosivitas hujan (R) dihitung dari interpretasi data hujan. Faktor tanaman (C) dan faktor pengelolaan lahan (P) ditentukan dari peta tataguna lahan. Faktor panjang dan kemiringan lereng (LS) dihitung dari data ASTER GDEM2. Faktor erodibilitas tanah $(\mathrm{K})$ ditentukan dari analisis peta jenis tanah. Selanjutnya, semua faktor digunakan untuk menghitung tingkat bahaya erosi menggunakan USLE. Hasil penelitian menunjukan bahwa rata-rata laju erosi di wilayah Jawa Timur sebesar 10,30 ton/ha/tahun. Hasil klasifikasi tingkat bahaya erosi (TBE) di Jawa Timur menunjukkan 78,71\% dari luas wilayah tergolong kelas sangat ringan (0-15 ton/ha/tahun); 10,75\% tergolong kelas ringan 15-60 ton/ha/tahun; 6,39\% tergolong pada kelas erosi sedang (60-180 ton/ha/tahun); dan 2,83\% tergolong kelas erosi berat (180-480 ton/ha/tahun). Hanya 1,31\% wilayah tergolong pada kelas erosi sangat berat ( $>480$ ton/ha/tahun). Hasil penelitian menunjukkan bahwa USLE dapat digunakan untuk prediksi erosi secara cepat pada wilayah yang luas.
\end{abstract}

Kata kunci: Erosi, USLE, GIS, Jawa Timur

\begin{abstract}
Erosion is an event of eroding soil that occurs naturally. However, human activities that change land use from natural (forestry, plantation, rural areas) to urban features can alter the erosion processes. Rapid calculation of erosion level for the wide area is necessary for the management and conservation planning. This research aims to analyze the erosion level in East Java area using USLE (Universal Soil Loss Equation) and GIS. The erosivity factor (R) is calculated from rainfall data. Vegetation factor (C) and the conservation factor (P) estimated from land use map. The length and slope factor (LS) are calculated from the ASTER GDEM2, and the erodibility factor (K) is obtained from interpretation of soil map. Furthermore, all factors were analysed to calculate erosion rate. The result shows that the average erosion rate in East Java regions is 10,30 tons/ha/year. The result also show that $78,71 \%$ area of East Java is classified as very low erosion rate (0-15 tons/ha/year); $10,75 \%$ classified as low erosion rate $(15-60$ tons/ha/year); $6,39 \%$ classified as moderate erosion rate (60-180 tons/ha/year); and 2,83\% is severe type (180480 tons/ha/year). Only 1,31\% from the total area is classified as very severe erosion rate ( $>480$ tons/ha/year). The result also shows that USLE can be used to facilitate rapid erosion prediction for wide area.
\end{abstract}

Keywords: Erosion rate, USLE, GIS, East Java,

Citation Taslim, R. K., Mandala, M., dan Indarto, I., (2019). Prediksi Erosi di Wilayah Jawa Timur: Penerapan USLE dan GIS. Jurnal Ilmu Lingkungan, 17(2), 323-332, doi:10.14710/jil.17.2.323-332

\section{Latar Belakang}

Erosi adalah peristiwa pengikisan padatan yang menghasilkan sedimen (Julien, 2010). Proses alami ini menyebabkan rusaknya partikel tanah sehingga menyebabkan terjadinya pembuangan bahan organik dan mineral secara tidak teratur (Gilley, 2005). Erosi yang terjadi secara terus menerus dapat berdampak pada lingkungan dan masyarakat. Perhitungan erosi diperlukan untuk menentukan tingkat bahaya erosi (TBE) dan menentukan nilai resiko erosi pada skala wilayah lokal, nasional maupun global (Terranova et al., 2009), (Silva et al., 2011).

Analisis tentang tingkat bahaya erosi penting dilakukan untuk mengetahui status erosi yang terjadi, apakah berada pada level rentan atau tidak rentan. Secara prinsip, pemodelan erosi adalah penggambaran secara matematik tentang proses penghancuran, perpindahan, dan deposisi partikel tanah di atas permukaan lahan. Pemodelan erosi tanah dapat digunakan sebagai alat untuk memprediksi kehilangan agregat tanah (Nearing, 1994). 
Ada banyak metode yang telah dikembangkan untuk menghitung atau memodelkan erosi. Pemodelan secara empiris didasarkan pada observasi dan biasanya bersifat statistik. Salah satu model prediksi erosi yang paling awal dan masih banyak digunakan di berbagai negara adalah model USLE (Universal Soil Loss Equation) (Wischmeier dan Smith, 1978). USLE memprediksi rata-rata erosi tanah dalam jangka waktu yang lama pada suatu luasan lahan dengan sistem pertanaman dan pengelolaan tertentu.

Pendugaan laju erosi dengan metode USLE umumnya dikombinasikan dengan teknologi GIS (Geographic Information System). Integrasi USLE dan GIS merupakan perpaduan yang sangat baik dan efisien untuk menghitung kehilangan agregat tanah (Devatha et al., 2015). GIS memungkinkan kita untuk menentukan distribusi parameter secara spasial. Setiap faktor pada USLE dihitung dengan menggunakan fasilitas yang ada pada perangkat lunak GIS (Dabral et al., 2008). Data yang dibutuhkan untuk USLE umumnya adalah peta topografi, peta penggunaan lahan, peta tanah dan peta hujan. Peta hujan diperoleh dari interpolasi data hujan dari stasiun meteorologi. Data topografi dapat diperoleh dari DEM (Digital Elevation Model). Peta tanah digital dikonversi dari peta tanah yang ada. Peta peruntukan atau penggunaan lahan dapat diperoleh dari interpretasi citra satelit (Yue-Qing et al., 2008). Menurut Prayitno et al., (2015) metode USLE yang dikombinasikan dengan GIS sangat efisien untuk menghitung tingkat bahaya erosi pada wilayah yang luas. Akurasi metode USLE sangat tergantung pada indeks panjang dan kemiringan lereng (LS), erosivitas hujan (R), erodibilitas tanah $(\mathrm{K})$, jenis vegetatif (tanaman penutup tanah) dan teknik konservasi (CP).

Tinjauan teoritis dan tinjauan pustaka tentang penerapan USLE dan prediksi Erosi juga telah banyak dilakukan oleh para peneliti. Misalnya, Smith (1999) membandingkan model USLE, SLEMSA (Soil Loss Estimation Model for Southern Africa), RUSLE (Revised Universal Soil Loss Equation) dan WEPP (Water Erosion Prediction Project) di Wilayah afrika selatan. Selanjutnya, Godone dan Stanchi (2011) telah merangkum hasil-hasil penelitian tentang teori dan penerapan berbagai model prediksi erosi pada berbagai kasus (soil protection, land management, engineering, soil conservation, fire degradation) dengan variabel lingkungan yang berbeda (arid and semi arid ecosystem) dan studi dari wilayah yang berbeda (Yunani, Spanyol, Portugal, Brazil dan Meksiko).

USLE sudah lama digunakan dan terus digunakan pada berbagai kasus. Di beberapa negara, integrasi USLE dan GIS telah digunakan untuk perencanaan dan perumusan konservasi tanah untuk pertanian, misalnya di Amerika bagian barat (Renard et al., 1991), di Denmark (Olsen et al., 1998), di Jepang (Mihara et al., 2005), di Turki (Baskan et al., 2009), di India (Bera, 2017), di Afrika Selatan (Smith, 1999) dan di Malaysia (Baban et al., 2001).
Umumnya, USLE digunakan untuk menghitung erosi pada level DAS. Misalnya aplikasi USLE pada DAS Kulhan di India (Devatha et al., 2015). USLE juga digunakan untuk perhitungan erosi pada DAS Oued El Makhazine di Maroko (Belasri dan Lakhouili, 2016) dan di DAS Geleda di Etiopia (Gashaw et al., 2017). Pada kasus yang lain, USLE juga dapat digunakan untuk memprediksi laju erosi pada wilayah yang lebih luas, yaitu pada skala nasional atau regional. Misalnya, Rao et al., (2015) menggunakan USLE sebagai tool untuk menghitung laju erosi (Soil erosion rate/SER) secara nasional dan menggambarkan sebarannya secara spasial. Penelitian (Rao et al., 2015) menghasilkan laju erosi rerata di wilayah Cina sebesar 9,39 ton/ha/tahun. Prediksi erosi pada skala nasional juga dilakukan di Hungaria (Pásztor et al., 2016) dan di Republik Ceko (Novotný et al., 2016).

Di Indonesia, USLE juga telah banyak diterapkan. Misalnya As-syakur (2008) telah melakukan prediksi erosi dengan menggunakan metode USLE dan GIS berbasis piksel di daerah tangkapan air danau Buyan. Prayitno (2015) telah melakukan analisis tingkat bahaya erosi dengan menggunakan metode USLE dan GIS di wilayah DAS Talawaan di Kabupaten Minahasa Utara. Saiya dan Murti (2017) menerapkan USLE untuk perhitungan erosi pada DAS Wae Heru dan DAS Wae Tonahitu di Ambon. Penelitian sebelumnya terkait aplikasi USLE dan GIS di wilayah jawa Timur juga telah banyak dilakukan. Kartika (2012) menggunakan USLE untuk memetakan dan membandingkan tingkat bahaya erosi pada dua Sub-DAS identik (Kloposawit dan Rawatamtu). Ashidiqi (2016) menggunakan USLE untuk pemetaan tingkat bahaya erosi di wilayah kerja UPT PSDA (Unit Pelaksana Teknis Pengelolaan Sumberdaya Air) di Malang. Wilayah UPT mencakup kabupaten Malang, Blitar, Kota Batu dan Tulungagung. Ariestansi (2016) menggunakan USLE dan GIS untuk memprediksi laju erosi dan mengklasifikasi-kan tingkat bahaya erosi (TBE) di wilayah Bondowoso, Situbondo dan Banyuwangi. Hariyadi (2016) melakukan analisis yang sama di wilayah Jember dan Lumajang. Aryanata (2016) melakukan analisis erosi di wilayah Kediri, Jombang, Nganjuk. Filahmi (2016) melakukan analisis yang sama di wilayah Madiun, Ponorogo, dan Trenggalek. Semua penelitian tersebut memprediksi TBE menggunakan USLE dan GIS.

Rumus umum USLE relatif sama, namun detail data masukan, rumus perhitungan untuk masingmasing komponen ( $\mathrm{R}, \mathrm{K}, \mathrm{LS}$, dan $\mathrm{CP}$ ) cukup bervariasi. Variasi juga dapat berupa input DEM yang digunakan, range nilai TBE, lokasi dan Luasan wilayah di mana USLE diterapkan. Tabel $\mathbf{1}$ merangkum beberapa kasus penerapan USLE untuk menghitung faktor panjang dan kemiringan lereng (LS) di berbagai negara.

Rumus LS yang digunakan untuk menghitung faktor LS (pada Tabel 1) juga bervariasi, sebagaimana tercantum pada Tabel 2 . 
Tabel 1. Variasi input DEM, range nilai TBE, lokasi dan Luasan wilayah di mana USLE diterapkan

\begin{tabular}{|c|c|c|c|c|c|c|c|c|c|}
\hline \multirow{2}{*}{ No } & \multirow{2}{*}{$\begin{array}{l}\text { Range of } \\
\text { LS factor }\end{array}$} & \multirow{2}{*}{ DEM } & \multirow{2}{*}{$\begin{array}{c}\text { Daerah } \\
\text { Penelitian }\end{array}$} & \multirow{2}{*}{ Negara } & \multirow{2}{*}{$\begin{array}{l}\text { Luas } \\
\text { (Ha) }\end{array}$} & \multicolumn{3}{|c|}{ TBE (ton/ha/tahun) } & \multirow{2}{*}{ Literatur } \\
\hline & & & & & & $\min$ & mean & $\max$ & \\
\hline 1 & 2 & 3 & 4 & 5 & 6 & 7 & 8 & 9 & 10 \\
\hline 1 & $0-28,19$ & $30 \times 30$ & Gelaga Watershed & Ethiopia & 25609 & 0 & - & 237 & $\begin{array}{l}\text { Gashaw T, Tulu T, \& Agraw } \\
\text { M (2017) }\end{array}$ \\
\hline 2 & $0-22$ & $30 \times 30$ & $\begin{array}{l}\text { Oved El Makhazine } \\
\text { Watershed }\end{array}$ & Morocco & 241400 & 0 & - & 735 & $\begin{array}{l}\text { Belasri A \& Lakhouili A } \\
(2016)\end{array}$ \\
\hline 3 & $0-170$ & $30 \times 30$ & Nisaca River Basin & Serbia & 284800 & 0 & 13,1 & $>80,1$ & $\begin{array}{l}\text { Zivotic L., Perovic V, } \\
\text { Jaramaz D, Dordevic A, } \\
\text { Petrovic R, dan Todorovic M } \\
\text { (2012) }\end{array}$ \\
\hline 4 & $\begin{array}{l}0,114- \\
68,21\end{array}$ & $90 \times 90$ & Kulhan Watershed & India & 95300 & 0 & 0,1783 & 556 & $\begin{array}{l}\text { Devatha PC, Desspande V \& } \\
\text { Renukrapasad MS (2015) }\end{array}$ \\
\hline 5 & $0-20$ & $30 \times 30$ & $\begin{array}{l}\text { Upper South Koel } \\
\text { Basin }\end{array}$ & India & 94249 & 0 & 12,2 & $>80$ & $\begin{array}{l}\text { Parveen R \& Kumar U } \\
(2012)\end{array}$ \\
\hline \multirow{2}{*}{6} & \multirow{2}{*}{$0-54,23$} & \multirow{2}{*}{$30 \times 30$} & \multirow{2}{*}{$\begin{array}{l}\text { Kasilian } \\
\text { Watershed }\end{array}$} & \multirow{2}{*}{ Iran } & \multirow{2}{*}{34286} & 0 & 104,52 & 4092 & \multirow{2}{*}{$\begin{array}{l}\text { Zare M, Pnagopoulus T, \& } \\
\text { Loures L (2017) }\end{array}$} \\
\hline & & & & & & 0 & 149,73 & 4558 & \\
\hline 7 & $0-10,23$ & $30 \times 30$ & Ikour Watershed & Morocco & 5500 & 0 & 0,68 & $>15$ & $\begin{array}{l}\text { Jazouli AE, Barakat A, Ghafri } \\
\text { A, Moutaki SE, Ettaqy A, dan } \\
\text { Khellouk R (2017 }\end{array}$ \\
\hline 8 & $0-360$ & $\begin{array}{l}\text { Kontur } \\
\text { interval } 20 \\
\mathrm{~m}\end{array}$ & $\begin{array}{l}\text { Wadi Kerak } \\
\text { catchment }\end{array}$ & Jordan & 19100 & 0 & 64 & 790 & $\begin{array}{l}\text { Farhan Y \& Nawaiseh S } \\
\text { (2015) }\end{array}$ \\
\hline \multirow[b]{2}{*}{9} & \multirow[b]{2}{*}{$0-1708$} & \multirow{2}{*}{$\begin{array}{l}\text { Kontur } \\
\text { interval } 10 \\
\mathrm{~m}\end{array}$} & \multirow[b]{2}{*}{ Penang Island } & \multirow[b]{2}{*}{ Malaysia } & \multirow[b]{2}{*}{28500} & - & 75,71 & - & \multirow{2}{*}{$\begin{array}{l}\text { Pradhan B, Chaudari A, } \\
\text { Adinarayana J, Manfred F, } \\
\text { Buchroithner (2011) }\end{array}$} \\
\hline & & & & & & - & 92,54 & - & \\
\hline 10 & $0-55$ & - & $\begin{array}{l}\text { Himalayan } \\
\text { atershed }\end{array}$ & Malaysia & 11300 & 0 & 26 & 61,315 & $\begin{array}{l}\text { Sheikh AH, Palria S \& Alam } \\
\text { A (2011) }\end{array}$ \\
\hline
\end{tabular}

Tabel 2. Variasi Rumus LS Menurut Input DEM

\begin{tabular}{|c|c|c|}
\hline No & Rumus utama & Literatur \\
\hline 01 & $\begin{array}{c}\text { LS }=(F A \text { sell sire } / 22.1)^{m}:\left(0.065+0.045 S+0.0065 s^{2}\right) \\
\text { FA }=\text { flow accumulation }\end{array}$ & Gashaw T, Tulu T, \& Agraw M (2017) \\
\hline 02 & 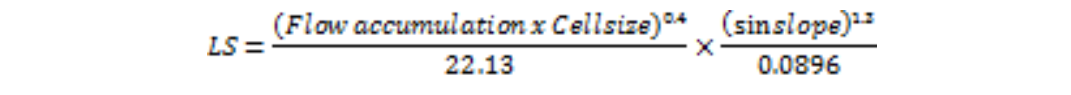 & Belasri A \& Lakhouili A (2016) \\
\hline 03 & $L S=\left(\frac{A}{2213}\right)^{2.8}(\sin B / 0.0896)^{2 x}$ & $\begin{array}{c}\text { Zivotic L., Perovic V, Jaramaz D, } \\
\text { Dordevic A, Petrovic R, dan Todorovic } \\
\text { M (2012 }\end{array}$ \\
\hline 04 & Tidak tercantum & $\begin{array}{c}\text { Devatha PC, Desspande V \& } \\
\text { Renukrapasad MS (2015) }\end{array}$ \\
\hline 05 & $L S=\left(\frac{\text { Flow accumulation } \times \text { grid size }}{22.1}\right)^{0.4} \times\left(\frac{\sin (\text { slope }) \times 0.01745}{0.09}\right)^{2.4}$ & Parveen R \& Kumar U (2012) \\
\hline 06 & Tidak tercantum & $\begin{array}{c}\text { Zare M, Pnagopoulus T, \& Loures L } \\
\text { (2017) }\end{array}$ \\
\hline 07 & $L S=\left(\text { Flow accumulation } \times \frac{\text { cell sire }}{22.13}\right)^{0.4} \times \sin \left(\frac{\text { slope }}{0.896}\right)^{2.3}$ & $\begin{array}{c}\text { Jazouli AE, Barakat A, Ghafri A, } \\
\text { Moutaki SE, Ettaqy A, dan Khellouk R } \\
\text { (2017 }\end{array}$ \\
\hline 08 & $L S=P o w\left([\right.$ flowace $\left.] \times \frac{\text { resolution }}{22.1}, 0.6\right) \times$ Pow $\left(\frac{(\sin [\text { slope gradient] } \times 0.01745)}{0.09}, 1.3\right)$ & Farhan Y \& Nawaiseh S (2015) \\
\hline 09 & $\begin{aligned} L=\left(\frac{x}{22.13}\right)^{m} s & =10.8 \sin \theta+0.03, \text { slopes steepness }<9 \%, \\
s & =16.8 \sin \theta+0.03, \text { slopes steepness }>9 \%\end{aligned}$ & $\begin{array}{l}\text { Pradha n B, Chaudari A, Adinarayana } \\
\text { J, Manfred F, Buchroithner (2011) }\end{array}$ \\
\hline 10 & Tidak tertulis di artikel & Sheikh AH, Palria S \& Alam A (2011) \\
\hline
\end{tabular}

Tabel 3. Kriteria kelas untuk klasifikasi besarnya TBE

\begin{tabular}{llllllllll}
\hline \multicolumn{2}{c}{ Ethiopia } & \multicolumn{2}{c}{ Serbia } & \multicolumn{2}{c}{ India } & \multicolumn{2}{c}{ Indonesia } & Kongo \\
\hline TBE & A & TBE & A & TBE & A & TBE & A & TBE & A \\
\hline Slight & $0-11$ & Slight & $<5$ & Slight & $<5$ & Very low & $0-15$ & Very low & $<1$ \\
\hline Moderate & $11-18$ & Moderate & $5-10$ & Moderate & $5-10$ & Low & $15-60$ & Low & $1.1-3$ \\
\hline Hard & $18-30$ & Hard & $10-20$ & Hard & $10-20$ & Moderate & $60-180$ & Low to medium & $3.1-5$ \\
\hline Very hard & $30-50$ & Very hard & $20-40$ & Very hard & $20-40$ & Severe & $180-480$ & Medium to hight & $5.1-10$ \\
\hline Severe & $50-327$ & Severe & $40-80$ & Severe & $40-80$ & Very severe & $>480$ & Hight & $10.1-15$ \\
\hline & & Very severe & $>80$ & Very severe & $>80$ & & & Very hight & $>15$ \\
\hline
\end{tabular}

Sumber:

1. Ethiopia (Gashaw et al, 2017); 2. Serbia (Životić et al., 2012); 3. India (Parveen dan Kumar, 1869) ;

4. Indonesia (Saiya, Dibyosaputro and Santosa, 2016) ; 5. Kongo (Kabantu et al., 2018) 
Kriteria kelas untuk menyatakan klasifikasi besarnya laju erosi yang dihasilkan dari perhitungan USLE juga bervariasi dari satu negara ke negara lain (Tabel 3).

Studi literatur menunjukkan bahwa USLE dapat digunakan untuk menghitung estimasi laju erosi pada luasan yang sebatas DAS, seluas wilayah kabupaten atau pada skala regional, nasional maupun kontinental. USLE telah diterapkan di berbagai belahan bumi dengan berbagai penyesuian lokal, namun dengan rumus yang relatif sama. Variasi input data dan detail rumus perhitungan komponen USLE, ditentukan oleh para peneliti dengan mempertimbangkan berbagai hal yang sifatnya lokal.

Penelitian ini bertujuan untuk menganalisis dan mengaklasifikasikan tingkat bahaya erosi (TBE) menggunakan metode USLE dan GIS pada skala yang lebih luas, yaitu pada seluruh wilayah Jawa Timur. Input data yang digunakan didapat dari berbagai sumber primer dan sekunder.

\section{Metodologi Penelitian \\ 2.1 Lokasi penelitian}

Lokasi Penelitian ini mencakup seluruh wilayah Provinsi Jawa Timur (Gambar 1). Secara administrasi Provinsi Jawa Timur mencakup wilayah 77 Kabupaten dan Kota dengan luas 47.042,17 km².

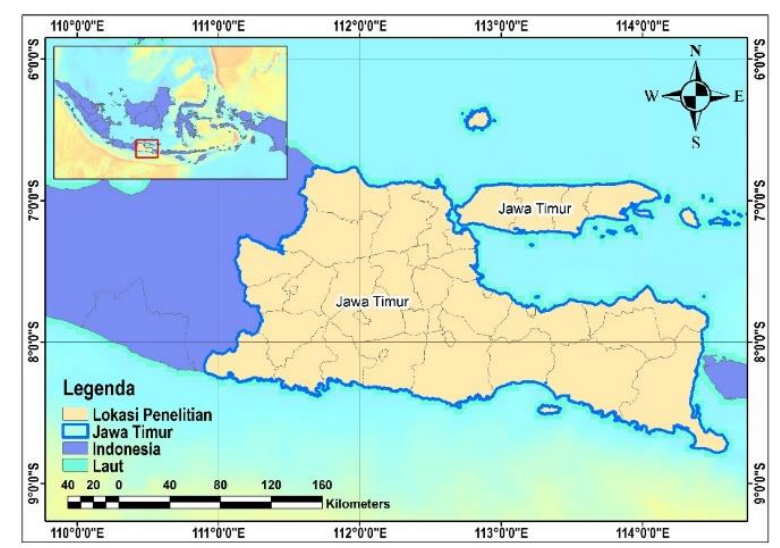

Gambar 1. Peta wilayah penelitian di Jawa Timur

Pengelohan data dilakukan di Laboraturium Teknik Pengendalian dan Konservasi Lingkungan (Lab. TPKL) Jurusan Teknik Pertanian Universitas Jember.

\subsection{Bahan dan Alat}

Bahan yang digunakan dalam penelitian ini adalah (1) data hujan yang diperoleh dari 749 stasiun hujan, dengan panjang periode rekaman dari tahun 2005 sampai 2014, (2) peta jenis tanah, (3) peta tata guna lahan, dan (4) data ASTER G-DEM2. Peralatan yang digunakan untuk analisis mencakup (1) PC, (2) perangkat lunak Excel dan (3) perangkat lunak GIS. Semua data yang digunakan ada pada database di Lab. TPKL.

\subsection{Tahapan Penelitian}

\section{Pengolahan data}

Data hujan yang digunakan adalah hujan tahunan. Hujan tahunan diperoleh dari kumulatif hujan harian dalam rentang waktu satu tahun. Periode rekaman hujan yang tersedia dan digunakan dari tahun 2005 sampai dengan tahun 2014. Data hujan digunakan untuk menghitung nilai faktor erosivitas hujan (R). Perhitungan faktor $R$ mengggunakan persamaan dari Bols (Teh et al., 2011):

$R=\frac{2,5 P^{2}}{100(0,073 P+0,73)}$

Keterangan:

$\mathrm{R}=$ indeks erosivitas rata-rata per tahun (MJ.mm/tahun)

$\mathrm{P}=$ curah hujan rata-rata tahunan ( $\mathrm{mm} /$ tahun$)$.

Setelah nilai $R$ untuk setiap stasiun hujan dihitung. Selanjutnya, dilakukan interpolasi terhadap data tersebut untuk membuat peta indeks erosivitas hujan (R). Interpolasi menggunakan metode IDW (Inverse Distance Weigthing). Prosedur interpolasi $I D W$ mengikuti metode yang sudah dipublikasikan di dalam Indarto (2013ab).

Peta jenis tanah diinterpretasi untuk menentukan nilai faktor $K$ (Indek Erodibilitas Tanah). Tabel 4 digunakan untuk menentukan nilai faktor $K$ untuk tiap jenis tanah. Kemudian nilai $K$ dimasukan sebagai atribut tabel pada layer faktor $K$. Selanjutnya, peta atau layer faktor $\mathrm{K}$ dikonversi menjadi raster menggunakan perangkat lunak GIS.

Data DEM didapatkan dari data ASTER GDEM2. Data DEM digunakan untuk menghitung nilai faktor LS. Data DEM diturunkan menjadi kemiringan lereng (slope), arah aliran (flow direction), dan akumulasi aliran (flow accumulation). Selanjutnya faktor LS dihitung dengan menggunakan raster calculator mengikuti persamaan 2 (Belasri dan Lakhouili, 2016):

$L S=\frac{(\text { FAx Cellsize })^{0.4}}{22,13} \times \frac{(\text { sin siope })^{1.3}}{0,0896}$

Keterangan :
LS = faktor panjang dan kemiringan lereng
FA = akumulasi aliran
Cellsize $=$ ukuran piksel
Slope $=$ kemiringan lereng $\left(^{\circ}\right)$

Peta RBI digital digunakan untuk menentukan nilai penggunaan lahan sebagai satu unit poligon. Selanjutnya, nilai CP ditentukan berdasarkan kriteria pada Tabel 5. Kemudian nilai CP dimasukan sebagai atribut tabel dan dikonversi menjadi raster. 
Tabel 4 Nilai faktor K Berdasarkan Jenis Tanah

\begin{tabular}{|c|c|c|}
\hline No & Tipe Tanah & Nilai faktor $\mathrm{K}$ \\
\hline 1 & Tanah eutropik organic & 0,301 \\
\hline 2 & Tanah hidromorphic alluvial & 0,156 \\
\hline 3 & Tanah abu-abu alluvial & 0,259 \\
\hline 4 & Tanah alluvial coklat keabu-abuan & 0,315 \\
\hline 5 & Alluvial abu-abu dan alluvial coklat keabu-abuan & 0,193 \\
\hline 6 & Kompleks tanah alluvial abu-abu dan tanah humic abu-abu & 0,205 \\
\hline 7 & Kompleks tanah alluvial abu-abu dan tanah humic rendah abu-abu & 0,202 \\
\hline 8 & Komplek tanah hydromorfic abu-abu dan planosol coklat keabu-abuan & 0,301 \\
\hline 9 & Planosol coklat keabu-abuan & 0,251 \\
\hline 10 & Komplek tanah litosol dan tanah mediteran merah & 0,215 \\
\hline 11 & Regosol abu-abu & 0,304 \\
\hline 12 & Komplek regosol abu-abu dan litosol & 0,172 \\
\hline 13 & Regosol coklat & 0,346 \\
\hline 14 & Regosol coklat kekunig-kuningan & 0,331 \\
\hline 15 & Regosol abu-abu kekuning-kuningan & 0,301 \\
\hline 16 & Komplek regosol dan litosol & 0,302 \\
\hline 17 & Andosol coklat & 0,278 \\
\hline 18 & Andosol coklat kekuning-kunigan & 0,223 \\
\hline 19 & Komplek andosol coklat dan regosol coklat & 0,271 \\
\hline 20 & Komplek rensinas, litosol dan tanah hutan coklat & 0,157 \\
\hline 21 & Grumosol abu-abu & 0,176 \\
\hline 22 & Grumosol abu-abu hitam & 0,187 \\
\hline 23 & Komplek grumosol, regosol dan tanah mediteran & 0,201 \\
\hline 24 & Komplek tanah mediteran coklat dan litosol & 0,323 \\
\hline 25 & Komplek tanah menditeran dan grumosol & 0,275 \\
\hline 26 & Komplek tanah menditeran coklat kemerahan dan litosol & 0,188 \\
\hline 27 & Latosol coklat & 0,175 \\
\hline 28 & Latosol coklat kemerahan & 0,121 \\
\hline 29 & Latosol coklat hitam kemerahan & 0,058 \\
\hline 30 & Latosol coklat kekuningan & 0,082 \\
\hline 31 & Latosol merah & 0,075 \\
\hline 32 & Latosol merah kekuningan & 0,054 \\
\hline 33 & Kompleks latosol coklat dan regosol abu-abu & 0,186 \\
\hline 34 & Kompleks latosol coklat dan kekuningan & 0,091 \\
\hline 35 & Kompleks latosol coklat kemerahan dan latosol coklat & 0,067 \\
\hline 36 & Kompleks latosol merah, latosol coklat kemerehan dan litosol & 0,062 \\
\hline 37 & Kompleks latosol merah dan latosol coklat kemerahan & 0,061 \\
\hline 38 & Kompleks latosol merah kekuningan, latosol coklat kemerahan dan latosol & 0,064 \\
\hline 39 & Komplek latosol coklat kemerahan dan litosol & 0,075 \\
\hline 40 & Kompleks latosol merah kekuningan, latosol coklat podsolik merah kekuningan dan litosol & 0,116 \\
\hline 41 & Tanah podsolik kuning & 0,167 \\
\hline 42 & Tanah podsolik merah kekunigan & 0,166 \\
\hline 43 & Tanah podsolik merah & 0,158 \\
\hline 44 & Komplek podsilik kuning dan tanah hydromorphic abu-abu & 0,249 \\
\hline 45 & Komplek tanah podsolik kuning dan regosol & 0,158 \\
\hline 46 & Komplek tanah podsolik kuning, podsolik merah kekunigan dan regosol & 0,175 \\
\hline 47 & Komplek lateritik merah kekuningan dan tanah podsolik merah kekuningan & 0,175 \\
\hline
\end{tabular}
Sumber: Ismaniar, (2012), Hendrawan, (2004).

Tabel 5. Nilai faktor pengelolaan tanaman dan tindakan konservasi (CP) menurut jenis peruntukan-nya.

\begin{tabular}{clc}
\hline No. & Konservasi dan Pengelolaan Tanaman & NilaiCP \\
\hline 1. & Hutan tak terganggu & 0,01 \\
2. & Hutan & 0,001 \\
3. & Hutan mangrove & 0,001 \\
4. & Hutan lahan kering primer & 0,03 \\
5. & Hutan lahan kering sekunder & 0,005 \\
6. & Semak belukar & 0,05 \\
7. & Sawah & 0,02 \\
8. & Pertanian lahan kering & 0,5 \\
9. & Pertanian lahan kering bercampur semak & 0,43 \\
10. & Lahan terbuka & 0,02 \\
11. & Perkebunan & 0,3 \\
12. & Permukiman/Tempat Tinggal & 1 \\
13. & Pertambangan & 1 \\
14. & Tambak & 0,001 \\
15. & Alang-alang & 0,02 \\
16. & Ladang & 0,28 \\
17. & Danau/Empang/Beting & 0,001 \\
18. & Rawa & 0,01 \\
19. & Sungai & 0,001 \\
\hline Sumber: Asdak, (2002), Fahliza et al., (2013)
\end{tabular}

\section{Perhitungan laju erosi}

Menurut Wischmeier dan Smith (1978), USLE menghitung laju erosi $(A)$ menggunakan persamaan 3:

$A=R \times K \times L \times S \times C P$.

Keterangan:

A = Jumlah tanah yang hilang rata-rata setiap tahun (t/ha/th atau t/acre/th)

$\mathrm{R}=$ faktor erosivitas curah hujan

$\mathrm{K} \quad$ = faktor erodibilitas tanah

LS = faktor panjang dan kemiringan lereng

$\mathrm{CP}=$ faktor pengelolaan tanaman (vegetasi)/ penutupan lahan.

Persamaan 3 dihitung menggunakan Raster Calculator. Proses perhitungan dilakukan setelah semua faktor USLE (R, K, LS, CP) sudah dalam format raster. 


\section{Hasil dan Pembahasan \\ 3.1 Hasil Analisis Faktor Erosi}

\section{Faktor erosivitas hujan (R)}

Erosivitas memiliki peran penting dalam menyebabkan terjadinya erosi. Sifat fisik hujan seperti tebal hujan, durasi hujan dan kecepatan jatuhnya hujan dapat mempengaruhi erosi. Gambar 2 , menampilkan sebaran spasial (variabilitas spasial) nilai erosivitas hujan $(R)$ hasil interpolasi IDW untuk semua wilayah Jawa Timur. Nilai erosivitas hujan tertinggi $=1391,97$ MJ.mm/tahun. Semakin tinggi nilai erosivitas hujan, maka kemampuan air hujan untuk menghancurkan agregat tanah semakin kuat. Hujan yang jatuh akan mengisi ruang pori makro akibatnya laju infiltrasi akan terhambat, dan limpasan permukaan akan meningkat (Widianto et al., 2014).

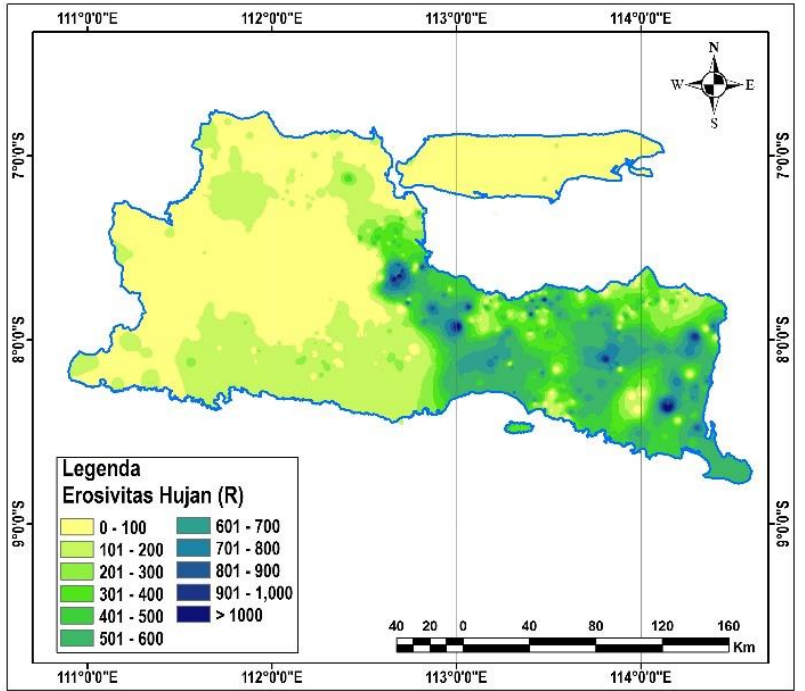

Gambar 2. Faktor Erosivitas hujan $(R)$ dengan Interpolasi IDW.

Tabel 6 Nilai Faktor K berdasarkan klasifikasi jenis tanah

\begin{tabular}{|c|c|c|c|c|c|}
\hline No & Jenis Tanah & $\begin{array}{c}\text { Luas } \\
\left(\mathrm{km}^{2}\right)\end{array}$ & $\begin{array}{c}\text { Luas } \\
(\%)\end{array}$ & Erodibilitas & $\begin{array}{c}\text { Tingkat } \\
\text { Erodibilitas } \\
\end{array}$ \\
\hline 1 & Latosol Merah Kekuningan & 37,9 & 0,1 & 0,054 & Sangat Rendah \\
\hline 2 & Latosol Coklat Kemerahan dan Latosol Coklat & 60,3 & 0,1 & 0,067 & Sangat Rendah \\
\hline 3 & Latosol Merah & 41,6 & 0,1 & 0,075 & Sangat Rendah \\
\hline 4 & Latosol Coklat Kemerahan & 2671,1 & 5,4 & 0,121 & Rendah \\
\hline 7 & Litosol & 1721,8 & 3,5 & 0,13 & Rendah \\
\hline 9 & Kompleks Regosol dan Litosol & 265,1 & 0,5 & 0,172 & Agak rendah \\
\hline 10 & Latosol Coklat & 203,6 & 0,4 & 0,175 & Agak rendah \\
\hline 11 & Grumusol Coklat Kekelabuan dan Kelabu Kekuningan & 49,7 & 0,1 & 0,176 & Agak rendah \\
\hline 12 & Kompleks Grumusol Kelabu dan Litosol & 200,2 & 0,4 & 0,176 & Agak rendah \\
\hline 13 & Latosol Coklat dan Regosol Kelabu & 2134,2 & 4,3 & 0,186 & Agak rendah \\
\hline 14 & Kompleks Grumusol Hitam dan Litosol & 13,5 & 0,0 & 0,187 & Agak rendah \\
\hline 15 & Grumusol Hitam & 189,0 & 0,4 & 0,187 & Agak rendah \\
\hline 17 & Grumusol Kelabu Tua & 4419,9 & 9,0 & 0,187 & Agak rendah \\
\hline 18 & Asosiasi Litosol dan Mediteran Coklat Kemerahan & 20,6 & 0,0 & 0,188 & Agak rendah \\
\hline 19 & Asosiasi Mediteran Coklat Litosol & 75,7 & 0,2 & 0,188 & Agak rendah \\
\hline 20 & Mediteran Coklat Kemerahan & 76,1 & 0,2 & 0,188 & Agak rendah \\
\hline 21 & Kompleks Mediteran Coklat Kemerahan dan Litosol & 4526,3 & 9,2 & 0,188 & Agak rendah \\
\hline 22 & Kompleks Mediteran Merah dan Litosol & 1938,7 & 3,9 & 0,188 & Agak rendah \\
\hline 24 & Aluvial Coklat Tua Kekelabuan & 14,1 & 0,0 & 0,193 & Agak rendah \\
\hline 25 & Asosiasi Aluvial Kelabu dan Coklat Kekelabuan Asos & 1899,8 & 3,9 & 0,193 & Agak rendah \\
\hline 26 & Asosiasi Mediteran Coklat dan Regosol & 21,7 & 0,0 & 0,201 & Sedang \\
\hline 27 & Mediteran Merah Tua dan Regosol & 311,0 & 0,6 & 0,201 & Sedang \\
\hline 28 & Kompleks Mediteran, Grumusol, Regosol dan Litosol & 1467,4 & 3,0 & 0,201 & Sedang \\
\hline 29 & Asosiasi Mediteran Coklat dan Regosol & 0,6 & 0,0 & 0,201 & Sedang \\
\hline 30 & Kompleks Litosol, Mediteran dan Renzina & 3408,6 & 6,9 & 0,215 & Sedang \\
\hline 31 & Kompleks Andosol Coklat/ Coklat Kekuningan, Litoso & 166,1 & 0,3 & 0,223 & Sedang \\
\hline 32 & Andosol Coklat Kekuningan & 247,5 & 0,5 & 0,223 & Sedang \\
\hline 34 & Aluvial Kelabu & 37,9 & 0,1 & 0,259 & Agak Tinggi \\
\hline 35 & Aluvial Kelabu Kekuningan & 52,2 & 0,1 & 0,259 & Agak Tinggi \\
\hline 36 & Asosiasi Glei Humus Rendah dan aluvial Kelabu & 552,4 & 1,1 & 0,259 & Agak Tinggi \\
\hline 37 & Asosiasi Andosol dan Regosol Coklat Kekuningan & 1642,6 & 3,3 & 0,271 & Agak Tinggi \\
\hline 38 & Mediteran Coklat Kemerahan dan Grumusol Kelabu & 424,5 & 0,9 & 0,275 & Agak Tinggi \\
\hline 40 & Andosol Coklat & 8,2 & 0,0 & 0,278 & Agak Tinggi \\
\hline 41 & Asosiasi Andosol Coklat dan Glei Humus & 121,0 & 0,2 & 0,278 & Agak Tinggi \\
\hline 43 & Regosol Coklat Kekelabuan & 476,2 & 1,0 & 0,301 & Tinggi \\
\hline 45 & Kompleks Regosol dan Litosol & 1399,7 & 2,8 & 0,302 & Tinggi \\
\hline 48 & Regosol Kelabu & 353,9 & 0,7 & 0,304 & Tinggi \\
\hline 49 & Asoiasi Andosol Kelabu dan Regosol Kelabu & 526,7 & 1,1 & 0,304 & Tinggi \\
\hline 51 & Aluvial Hidromorf & 5488,2 & 11,2 & 0,312 & Tinggi \\
\hline 52 & Aluvial Coklat Kekelabuan & 2740,0 & 5,6 & 0,315 & Tinggi \\
\hline 54 & Asosiasi Litosol dan Mediteran Coklat Kemerahan & 24,6 & 0,1 & 0,323 & Tinggi \\
\hline 55 & Asosiasi Mediteran Coklat Litosol & 90,6 & 0,2 & 0,323 & Tinggi \\
\hline 56 & Kompleks Mediteran Coklat dan Litosol & 1352,7 & 2,7 & 0,323 & Tinggi \\
\hline 58 & Mediteran Coklat & 3308,4 & 6,7 & 0,323 & Tinggi \\
\hline 59 & Asosiasi Non Calcic Brown dan Regosol & 91,1 & 0,2 & 0,331 & Tinggi \\
\hline 60 & Regosol Coklat Kekuningan & 145,2 & 0,3 & 0,331 & Tinggi \\
\hline 61 & Regosol Coklat & 3616,2 & 7,4 & 0,346 & Tinggi \\
\hline \multirow[t]{2}{*}{63} & Brown Forest Soil & 554,8 & 1,1 & 0,56 & Sangat Tinggi \\
\hline & Total & 49189,1 & 100,0 & & \\
\hline
\end{tabular}


Pada penelitian ini tidak dilakukan analisis curah hujan berdasarkan intensitas hujan dan ukuran diameter butiran hujan sehingga tidak dapat dianalisis besarnya energi hujan yang berpotensi menyebabkan erosi.

\section{Faktor erodibilitas tanah $(K)$}

Erodibilitas tanah merupakan salah satu yang mempengaruhi erosi. Erodibilitas tanah (K) menyatakan kepekaan suatu tanah terhadap erosi. Nilai erodibilitas suatu tanah ditentukan oleh ketahanan tanah terhadap daya rusak dari luar dan kemampuan tanah untuk menyerap air (Utomo, 1994). Hasil analisis jenis tanah pada lokasi penelitian disajikan pada Tabel 6.

Wilayah Jawa Timur didominasi oleh jenis tanah alluvial hidromorf. Luas alluvial hidromorf $=5488$ $\mathrm{km}^{2}$ atau $11,2 \%$ dari total luasan keseluruhan. Gambar 3, menampilkan peta erodibilitas tanah $(K)$.

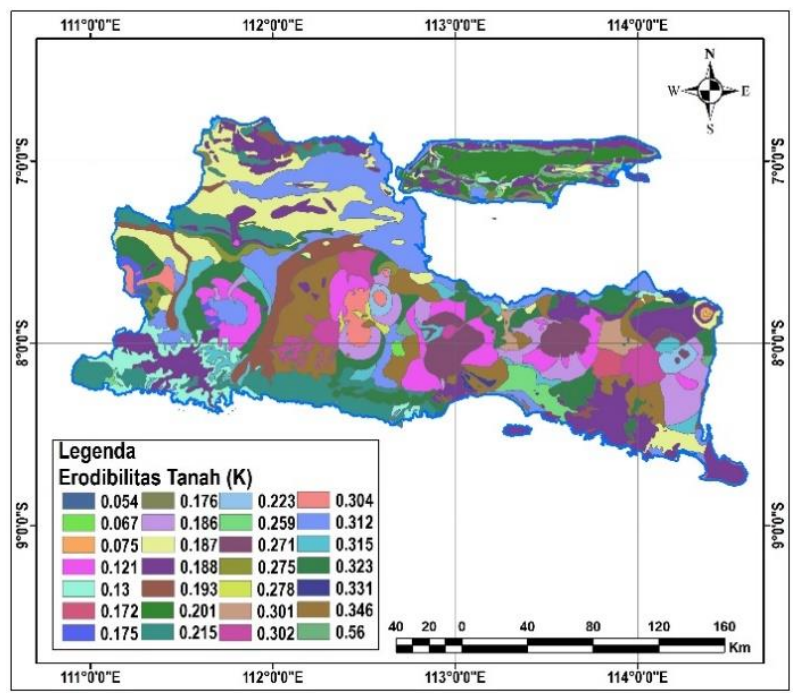

Gambar 3. Peta faktor erodibilitas $(K)$

3. Faktor panjang dan kemiringan lereng (LS)

Tabel 7 Nilai faktor LS di Jawa Timur (gambar 4)

\begin{tabular}{cccccc}
\hline No & Klasifikasi LS & Luas (Ha) & Luas (\%) & Keterangan \\
\hline $\mathbf{1}$ & $0-3$ & 3268030,32 & 69,73 & Datar \\
$\mathbf{2}$ & $3 .-8$ & 706317,03 & 15,07 & Landai \\
$\mathbf{3}$ & $8-15$ & 362370,78 & 7,73 & Agak Curam \\
$\mathbf{4}$ & $15-30$ & 227164,95 & 4,85 & Curam \\
$\mathbf{5}$ & $>30$ & 122868,09 & 2,62 & Sangat Curam \\
& Total & 520492,95 & 100 & \\
\hline
\end{tabular}

Sumber: Kartika, 2012.

Nilai faktor panjang dan kemiringan lereng (LS) yang dominan adalah nilai LS $=0-3$, seluas $3.268 .030,32$ ha atau $69,73 \%$ dari total Luas Jawa Timur. Kemiringan lereng yang lebih curam, akan menyebabkan erosi lebih besar. Selain kemiringan, panjang lereng juga mempengaruhi besarnya erosi. Semakin panjang suatu lereng akan semakin banyak volume tanah yang terbawa oleh aliran permukaan (Arsyad, 1989).

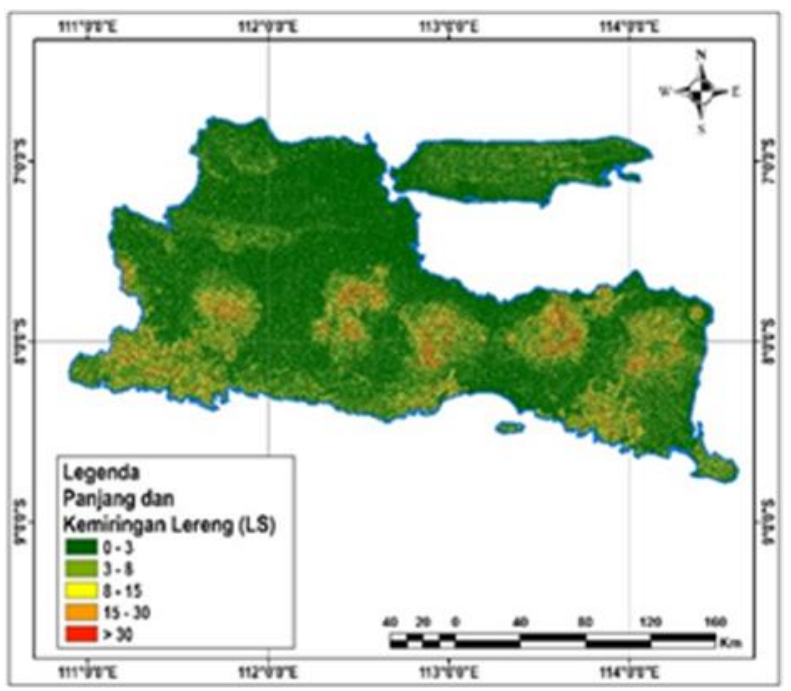

Gambar 4. Peta Kemiringan dan Panjang Lereng (Ls).

Nilai faktor LS yang tinggi terjadi pada lokasi akumulasi aliran. Sehingga jumlah erosi tanah akan semakin tinggi pada piksel di tempat terjadinya akumulasi aliran. Nilai faktor LS disajikan pada Gambar 4.

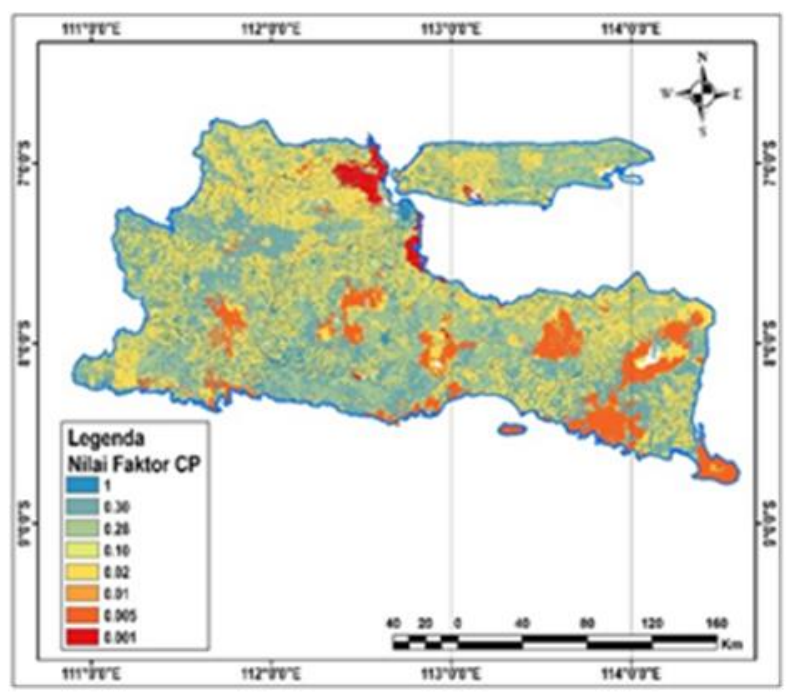

Gambar 5. Peta faktor CP pada tahun 2014 di Jawa Timur

\section{Faktor pengelolaan tanaman dan tindakan konservasi (CP)}

Vegetasi tanaman dan tindakan konservasi tanah (CP) merupakan faktor penting dalam menentukan besarnya erosi. Hal ini disebabkan faktor CP merupakan faktor yang dapat dikendalikan 
oleh manusia. Hasil dari interpretasi penggunaan lahan di wilayah Jawa Timur disajikan pada Tabel 8.

Sebagian besar penggunaan lahan di lokasi penelitian (perumahan, pertanian lahan kering, ladang, alang-alang, dan sawah) memiliki nilai CP yang tinggi dibandingkan hutan. Penggunaan lahan dengan nilai CP yang tinggi menunjukkan bahwa vegetasi yang ada belum cukup untuk mengendalikan erosi. Selain itu nilai CP tinggi juga menunjukkan bahwa tidak ada penerapan tindakan konservasi tanah yang dilakukan.

Vegetasi sangat penting dalam mengurangi laju erosi. Kanopi dari vegetasi sangat baik dalam mengurangi besarnya daya hancur hujan, sedangkan akar dan batang vegetasi dapat membantu mengikat tanah dan air, sehingga akan mengurangi laju erosi (Munandar et al, 2016).

Tabel 8. Faktor CP Tahun 2014 di Jawa Timur

\begin{tabular}{|c|c|c|c|c|c|}
\hline No & Jenis Tata Guna Lahan & Luas (Ha) & Luas $\left(\mathrm{km}^{2}\right)$ & Luas (\%) & CP \\
\hline 1 & Alang-Alang & 35959,05 & 359,59 & 11,79 & 0,02 \\
\hline 2 & Beting & 184,23 & 1,84 & 0,06 & 0,001 \\
\hline 3 & Danau & 359,46 & 3,59 & 0,12 & 0,001 \\
\hline 4 & Empang & 8190,09 & 81,90 & 2,68 & 0,001 \\
\hline 5 & Hutan Lahan Kering & 40192,92 & 401,93 & 13,17 & 0,005 \\
\hline 6 & Perkebunan & 79317,90 & 793,18 & 26,00 & 0,3 \\
\hline 7 & Ladang & 77471,73 & 774,72 & 25,39 & 0,28 \\
\hline 8 & Permukiman & 48120,66 & 481,21 & 15,77 & 1 \\
\hline 9 & Rawa & 493,02 & 4,93 & 0,16 & 0,01 \\
\hline 10 & Sawah & 12614,49 & 126,14 & 4,13 & 0,02 \\
\hline 11 & Semak belukar & 13,23 & 0,13 & 0,00 & 0,1 \\
\hline 12 & Sungai & 1875,78 & 18,76 & 0,61 & 0,001 \\
\hline 13 & Tambak & 0,81 & 0,01 & 0,00 & 0,001 \\
\hline \multirow[t]{2}{*}{14} & Tempat Tinggal & 313,83 & 3,14 & 0,10 & 1 \\
\hline & Total & 305107,20 & 3051,07 & 100,00 & \\
\hline
\end{tabular}

\subsection{Tingkat Bahaya Erosi (TBE)}

Hasil perhitungan nilai laju erosi di wilayah Jawa Timur disajikan pada Tabel 9. TBE di Jawa Timur didominasi dengan tipe sangat ringan 0-15 ton/ha/tahun dengan total luas keseluruhan sebesar $78,71 \%$. Selanjutnya, pada (TBE) tipe ringan 15-60 ton/ha/tahun dengan total luas keseluruhan $10,75 \%$.
TBE tipe sedang antara 60-180 ton/ha/tahun dengan total luas keseluruhan 6,39\%. TBE tipe berat berkisar antara 180-480 ton/ha/tahun dengan total luas keseluruhan 2,83\%, dan tingkat bahaya erosi pada tipe sangat berat $>480$ ton/ha/tahun dengan total luas keseluruhan 1,31\%.

Tabel 9. Klasifikasi Tingkat Bahaya Erosi (TBE) di Jawa Timur

\begin{tabular}{|c|c|c|c|c|c|}
\hline No & Tingkat Bahaya Erosi (Ton/Ha/Th) & $\begin{array}{l}\text { Luas } \\
\text { (ha) }\end{array}$ & $\begin{array}{l}\text { Luas } \\
(\%)\end{array}$ & Erosi (Ton/ha/th) & Kondisi \\
\hline 1 & $0-8$ & 3395308,32 & 73,73 & 0,8 & Sangat Ringan \\
\hline 2 & $8-15$ & 229255,83 & 4,98 & 11,11 & Sangat Ringan \\
\hline 3 & $15-60$ & 495147,96 & 10,75 & 32,33 & Ringan \\
\hline 4 & $60-180$ & 294209,37 & 6,39 & 103,76 & Sedang \\
\hline 5 & $180-480$ & 130339,35 & 2,83 & 285,07 & Berat \\
\hline
\end{tabular}

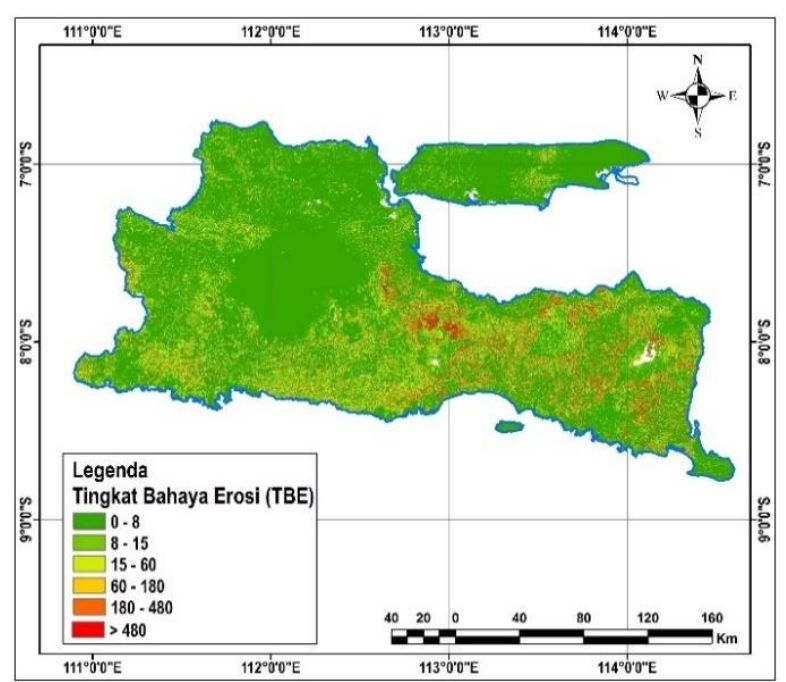

Perhitungan laju erosi bermanfaat sebagai alat bantu untuk mengambil keputusan dalam perencanaan konservasi lahan. Apabila laju erosi sudah dapat ditetapkan, maka dapat ditentukan kebijakan penggunaan lahan dan tindakan konservasi yang diperlukan agar tidak terjadi kerusakan yang lebih besar. Sehingga lahan dapat digunakan secara produktif dan berkelanjutan. Selain meningkatkan TBE, intensitas hujan yang tinggi akan meningkatkan resiko terjadinya bencana alam seperti erosi dan tanah longsor.

\section{Kesimpulan}

Analisis erosi dan tingkat bahaya erosi telah dilakukan untuk seluruh wilayah Jawa Timur. Faktor erosi yang terdiri dari faktor erosivitas curah hujan $(\mathrm{R})$, faktor erodibilitas tanah $(\mathrm{K})$, faktor pengelolaan 
tanaman dan tindakan konservasi (CP), serta faktor panjang dan kemiringan lereng (LS)digunakan sebagai input utama. Selanjutnya laju erosi dihitung dengan menggunakan tool raster calculator.

Hasil penelitian menunjukan bahwa rata-rata laju erosi di Jawa Timur sebesar 10,30 ton/ha/tahun, sedangkan klasifikasi tingkat bahaya erosi (TBE) di Jawa Timur didominasi oleh tipe erosi sangat ringan, yang nilainya antara 0 sd 15 ton/ha/tahun. Erosi jenis ini mencakup $78,71 \%$ dari luas total wilayah. Sementara, tingkat bahaya erosi (TBE) tipe: ringan 15-60 ton/ha/tahun dan mencakup 10,75\% luas jawa timur. Selanjutnya, TBE tipe sedang antara 60180 ton/ha/tahun mencakup 6,39\% luas total. Hanya sekitar $2,83 \%$ dari total luas yang berada pada TBE tipe berat (180-480 ton/ha/tahun) dan 1,31\% luas wiayah tergolong pada resiko erosi tipe sangat berat (>480 ton/ha/tahun).

\section{Ucapan Terima Kasih}

Data yang dalam penelitian ini berasal dari koleksi data yang ada di lab. Teknik Pengendalian dan Konservasi Lingkungan (TPKL), FTP Unej. Data berasal dari berbagai sumber dan dikoleksi melalui berbagai skema penelitian kerjasama, magang, dan skripsi mahasiswa. Ucapan terima kasih disampaikan kepada semua pihak yang telah membantu dalam terlaksananya penelitian ini, antara lain: PS Magister Pengelolaan Sumber Daya Air Pertanian (PSDAP), Fakultas Pascasarjana-Universitas Jember, Dinas PU Pengairan Provinsi, BIG, Balai Penelitian Hidrologi dan Sumberdaya air, LP2M UNEJ, DRPM-Dikti, dan para mahasiswa TEP yang telah membantu dalam analisis data (Astarina Ayu Ambarwati, Novitasari, Tanjung, Fauqi, Hariadi, Holilul rohman). Publikasi penelitian didanai dari Hibah Penelitian Pasca Sarjana (PPS-PTM)- DRPM - kementrian Ristek Dikti) tahun 2019 a.n Indarto.

\section{DAFTAR PUSTAKA}

Arsyad, S. 1989. Konservasi Tanah dan Air. Bogor: IPB Press.

Aryanata, R. A. 2016. Prediksi Tingkat Bahaya Erosi Menggunakan Pemodelan Universal Soil Loss equation (USLE) dan ArcGIS di Wilayah Administratif UPT PSDA Kediri. Skripsi. Jember: Universitas Jember.

Asdak, C. 2002. Hidrologi dan Pengelolaan Daerah Aliran Sungai. Yogyakarta: Gajah Mada University Press.

Ashidiqi, R. 2016. Pemetaan Tingkat Bahaya Erosi Menggunakan Universal soil Loss Equation (USLE) dan ArcGIS di Wilayah Administratif UPT PSDA Malang-Jawa Timur. Skripsi. Jember: Universitas Jember.

Ariestanti. T. A. D. 2016. Prediksi Tingkat Bahaya Erosi di Wilaah UPT PSDA Bondowoso Menggunakan USLE (Universal Soil Loss Equation) Integrasi ArcGIS. Skrips. Jember: Universitas Jember.

As-Syakur, A. 2008. Prediksi Erosi dengan Menggunakan Metode USLE dan Sistem Informasi Geografis
(SIG) Berbasis Piksel di Daerah Tangkapan Air Danau Buyan. PIT Mapin XVII. Bandung.

Auliyani, D., dan W.W. Wijaya. 2017. Perbandingan Prediksi Hasil Sedimen Menggunakan Pendekatan Model Universal Soil Loss Equation dengan Pengukuran Langsung. Jurnal Penelitian Pengelolaan Daerah Aliran Sungai. 1(1): 61-71.

Baban, S.M.J dan K.W. Yusof. 2009. Modelling soil erosion in tropical environments using remote sensing and geographical information systems. Hydrological Sciences Journal. 46(2): 191-198.

Baskan, O., H. Cebel, dan S. Akgul. 2010. Conditional Simulation of USLE/RUSLE Soil Erodibility Factor by Geostatistics in a Mediterranean Catchment Turkey. Enviromental Earth Sciences. 60(6): 1179-1187.

Belasri, A., dan Lakhouili, A. 2016. Estimation of Soil Erosion Risk Using the Universal Soil Loss Equation (USLE) and Geo-Information Technology in Oued El Makhazine Watershed, Morocco. Journal of Geographic Information System. 8: 98-107.

Bera, I. 2017. Assessment of Soil Loss by Universal Soil Loss Equation (USLE) Model Using GIS Techniques: a Case Study of Gumti River Basin, Tripura, India. Modeling Earth Systems and Environment. 2017. 3:29(1-9).

Dabral, P. P.; Baithuri, N.; Pandey, A. (2008). Soil Erosion Assessment in a Hilly Catchment of North Eastern India Using USLE, GIS and Remote Sensing. Water Resources Management, 22:1783-1798.

Devatha, C.P., V. Deshpande, dan M.S. Renukaprasad. 2015. Estimation of Soil Loss Using USLE Model for Kulhan Watershed Chatitisgarh. Aquatic Procedia. 4:1429-1436.

Edriani, A. F, Amri, K., dan Barchia, M. F. 2014. Analisis Tingkat Erosi dan Kekritisan Lahan Menggunakan Sistem Informasi Geografis di Sub DAS Bengkulu Hilir DAS Air Bengkulu. Tesis. Bengkulu: Universitas Bengkulu.

Fahliza, U., Anugerah, P., dan Dwi, D. 2013. Analisis Erosi pada SubDAS Lematang Hulu. Jurnal Teknik Sipil dan Lingkungan. 1(1), pp 32-39.

Farhan Y dan Nawaiseh S. 2015. Spatial Assesment of Soil Erosion Risk Using RUSLE and GIS Techniques. Environmental Earth Sciences. 74:4649-4669.

Filahmi, F.B. 2016. Analisis Spasial Pemodelan Universal Soil Loss Equation (USLE) di Wilayah UPT PSDA Madiun (Studi Kasus DAS Madiun-Ngawi). Skripsi. Jember: Universitas Jember.

Gashaw, T., Tulu, T. and Argaw, M. 2017. Erosion risk assessment for prioritization of conservation measures in Geleda watershed, Blue Nile basin, Ethiopia. Environmental Systems Research. 6(1):1-14.

Godone, D., dan Stanchi, S. 2011. Soil Erosin Issues in Agriculture. New York: Intech Publishers.

Gilley, J. E. 2005. Erosion water-induced. Encyclopedia of Soils in the Environment. 463-469.

Hariyadi. 2016. Perkiraan Tingkat Bahaya Erosi Menggunakan Universal Soil Loss Equation (USLE) dan GIS di Wilayah UPT PSDA Lumajang. Skripsi. Jember: Universitas Jember

Hendrawan, H. 2004. Aplikasi Sistem Informasi Geografi (SIG) untuk Pendugaan Erosi dengan Pendekatan USLE (Universal Soil Loss Equation) di Sub-DAS Cimuntur Ciamis. Skripsi. Bogor: Jurusan Teknologi Pertanian, IPB. 
Indarto, 2013a. Analisis Geostatistik. Yogyakarta: Graha Ilmu.

Indarto, 2013b. Variabilitas Spasial Hujan Harian di Jawa Timur. Jurnal Teknik Sipil. 20(2):107-120.

Ismaniar, R. A. 2012. Pendugaan Neraca Air menggunakan Aplikasi Tank Model dan Laju Sedimen dengan Metode MUSLE di Sub DAS Melamon Kabupaten Malang. Digital Times.

Jazouli, A., Ahmed, M., dan Barakat, A. 2017. Soil erosion modeled with USLE, GIS , and remote sensing : a case study of Ikkour watershed in Middle Atlas ( Morocco J', Geoscience Letters. 4-25

Julien, P. Y. 2010. Erosion and Sedimentation. 2nd edition. Cambridge: Cambridge University Press.

Kabantu, M. T., Thimanga, R. M., Kileshye, J. M. O., Gumindoga, W., dan Beya, J. T. 2018. A GIS-based estimation of soil erosion parameters for soil loss potential and erosion hazard in the city of Kinshasa, the Democratic Republic of Congo. Copernicus Publications on Behalf of the International Association of Hydrological Sciences. 378:51-57.

Kartika, I. 2012. Aplikasi Pemodelan USLE (Universal Soil Loss Equation) untuk Pemetaan Tingkat Bahaya Erosi di Sub-DAS Kloposawit dan Rawatantu. Skripsi Jember: Universitas Jember.

Mihara, M., N. Yamamoto, dan T. Ueno. 2005. Application of USLE for the Prediction of Nutrient Losses in Soil Erosion Processes. Paddy and Water Environment. 3(2): 111-119.

Munandar, R., Jayanti, D. S., dan Mustafril. 2016. Pemodelan Intersepsi Untuk Pendugaan Aliran Permukaan. Jurnal Ilmiah Teknologi Pertanian Agrotechno. 1(1):62-69.

Nearing, M. A. 1994. Detachment of Soil by Flowing Water Under Turbulent and Laminar Conditions. Soil Science Society of America Journal.

Novotny, I., Zizala, D., dan Kapicka, J. 2016. Monitoring Soil Erosion of Agricultureal Land in Czech Republic and Data Assesment of Erosion Events from Spatial Database. Proceedings from Inernational Conference Soil. 34-370.

Olsen, P., dan R. Kristensen. 1998. Using a GIS System in Mapping Risks of Nitrate Leaching and Erosion on the Basis of Soil-N and USLE Simulations. Nutrient Cycling in Agroecosystems. 5:307-311.

Parveen, R. and Kumar, U. 2012. Integrated Approach of Universal Soil Loss Equation (USLE) and Geographical Information System (GIS) for Soil Loss Risk Assessment in Upper South Koel Basin, Jharkhand, Journal od Geographic Information System. 4(6):588-596

Pasztor, L., Negyesi, G., Laborczi, A., Kovacs, T., Laszlo, E., dan Bihari, Z. 2016. Integrated Spatial Assesment of Wind Erosion Risk in Hungary. Hazards Earth System Science. 16(11):2421-2432

Pradhan, B., Jagarlapudi, A. and Buchroithner, M. 2011. Soil erosion assessment and its correlation with landslide events using remote sensing data and GIS : a case study at Penang Island, Malaysia. Environmental Monitoring and Assessment. 184(2):715-727
Prayitno, J.S. Tasirin, M.Y.M.A. Sumakud, dan J.A. Rombang. 2015. Pemanfaatam Sistem Informasi Geografis (SIG) Dalam Pengklasifikasian Bahaya Erosi Pada DAS Talawaan. Jurnal Ilmiah Fakultas Pertanian Universitas Sam Ratulangi. 6(11):1-8

Rao, E., Xiao, Y., Ouyang, Z. Yu, X. 2015. National Assessment of Soil Erosion and Its Spatial Patterns in China. Ecosystem Health and Sustainabillity. 1(4):1-10

Renard, K.G., G.R. Foster, G.A. Weesies, dan J.P. Porter. 1991. RUSLE (Revised Universal Soil Loss Equation). Journal Soil and Water Conservation. 46(1): 3033.

Saiya, H. G., Dibyosaputro, S. dan Santosa, S. H. B. 2016. USLE Estimation for Potential Erosion at Wae Heu Watershed and Wae Tonahitu Watershed, Ambon Island, Indonesia, Indonesian Journal of Geography, 48(2):191-205.

Sheikh, A., Palria, S., Alam, A. 2011. Integration of GIS and Universal Soil Loss Equation (USLE) For Soil Loss Estimation in a Himalayan Watershed. Geography and Geology. 3(3):51-57

Silva, A. M., Alcarde, C. and Hitomi, C. 2011. Natural Potential for Erosion for Brazilian Territory. Soil Erosion Studies. 1-24

Smith. 1999. Application of Empirical Soil Loss Models in Southern Africa: a review. South African Journal of Plant and Soil. 16(3): 158-163.

Terranova, O., Antronico, L., Coscarelli, R., Ianquita, P. 2009. Soil Erosion Risk Scenarios in the Mediterranean Environment Using RUSLE and GIS: An Application Model for Calabria (Southern Italy). Geomorphology. 112:228-245.

Teh, S. H. (2011). Soil Erosion Modeling Using RUSLE and GIS on Cameron Highlands, Malaysia For Hydropower Development. University of Iceland dan University of Akureyri. http://hdl.handle.net/1946/7751.

Utomo, W.H. 1994. Erosi dan Konservasi Tanah. Malang: IKIP Malang

Widianto, A dan Damen, M. 2014. Determination of Coastal Belt in the Disaster Prone Area: A Case Study in the Coastal Area of Bantul Regency, Yogyakarta, Indonesia. Indonesian Journal of Geography. 46(2):125-137

Wischmeier, W.H dan D. D. Smith. 1978. Predicting Rainfall Erosion Losses A Guide to Conservation Planning. Washington DC: Goovernment Printing Office.

Yue-Qing, X., Xiao-Mei, S., Xiang-Bin, K., Jian, P., Yun-Long, C. 2008. Adapting the RUSLE and GIS to Model Soil Erosion Risk in a Mountains Karst Watershed, Guizhou Province, China. Environment Monitoring Assessment. 141:275-286.

Zare, M., Panagopoulos, T., dan Loures, L. 2017. Simulating the Impacts of Future Land Use Change on Soil Erosion in the Kasilian Watershed, Iran, Elsevier. 67:558-572.

Životić, L., Perovic, V., Jaramaz, D., dan Djordevic. 2012. Application of USLE, GIS, and Remote Sensing in the Assessment of Soil Erosion Rates in Southeastern Serbia, Polish Journal of Environmental Studies, 21(6):. 1929-1935 